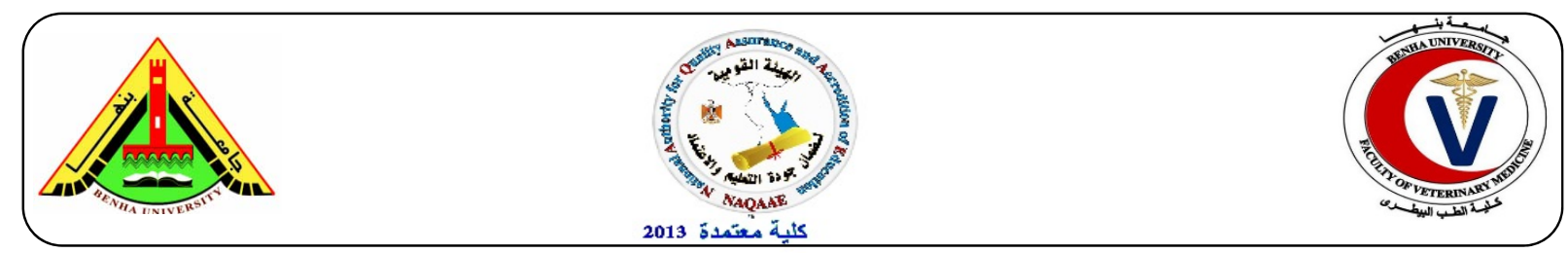

\title{
Biochemical effect of renal prophylactic drugs on inflammatory markers in experimentally induced chronic renal failure in rats.
}

\author{
${ }^{1}$ Abdel-Maksoud, H.A., ${ }^{2}$ Hindawi, U.M., ${ }^{2}$ Sadek, K.M. \\ ${ }^{1}$ Biochemistry Department, Faculty of Veterinary Medicine, Benha University, Egypt. ${ }^{2}$ Biochemistry Department, Faculty \\ of Veterinary Medicine, Damanhour University, Egypt.
}

\section{A B S T R A C T}

The present study aimed to determine the biochemical alternations and inflammatory markers in experimental induced chronic renal failure in rats by adenine at dose of $250 \mathrm{mg} / \mathrm{kg}$. b.w for two and four weeks and role of N-acetyl Cysteine on chronic renal failure as a prophylactic drug at dose of $54 \mathrm{mg} / \mathrm{kg}$ for two and four weeks

Key words: Chronic renal failure, Adenine, $\mathrm{N}$-acetyl cysteine.

(http://www.bvmj.bu.edu.eg)

(BVMJ-31(2): 176-180, 2016)

\section{INTRODUCTION}

The kidneys are important to perform the following functions: remove waste products from the body as (Urea, Creatinine and Uric acid), remove drugs form the body, balance the body's fluids( regulation of urinary excretion of Water, Hydrogen and Electrolytes), secrete Hormones (Angiotensin) which regulate blood pressure, produce an active form of vitamin $\mathrm{D}$ that promotes strong, healthy bones, control the production of red blood cells by Erythropoietin and calcium homeostasis (Naughton, 2008). Expectedly, when the kidneys fail, toxins accumulate and result in serious health complications as a result of their effect on the blood, brain and heart. These complications lead to renal failure and fatal disease if neglected (Gunsch, 2012).

Compounds that retained to increase in the blood and tissues during the development of end stage renal disease (ESRD) are defined as uremic retention solutes (Van holder et al., 2003). Expectedly, these uremic retention solutes accumulate in the patient's blood or tissues with chronic kidney disease (CKD) because of the lack of kidney clearance. Therefore, the purpose of renal replacement therapy, such as hemodialysis is to remove endogenous and exogenous toxins and to maintain fluid, electrolytes and acid base balance until the normal renal function returns or until a kidney replacement was found (Andereoli, 1999).

While, N-acetyl cysteine (NAC) is a thiol (sulfhydryl-containing) compound which has the chemical formula $\mathrm{C} 5 \mathrm{H} 9 \mathrm{NO} 3 \mathrm{~S}$ and a molecular weight of 163.2 (Ziment, 2007), it is rapidly absorbed following an oral dose; however, extensive first pass metabolism by the cells of the small intestine and the liver results in the incorporation of NAC into protein peptide chains and the formation of a variety of metabolites of NAC. Only a small percentage of the intact NAC molecule arrives in the plasma, and subsequently in tissue (De Caro et al., 2006).

Mechanisms of Action: N-acetyl cysteine (NAC) can stimulate glutathione (GSH) synthesis, enhance glutathione-S-transferase activity, promote detoxification, and act directly on reactive oxidant radicals (De Vries and De Flora, 2003) and $\mathrm{NAC}$ is able to enhance the intracellular biosynthesis of GSH. In cell culture experiments, NAC promotes the uptake of cysteine from the culture medium for cellular GSH biosynthesis (Issels et al., 2008).

The objectives of this work were two folds: To determine the biochemical alternations and inflammatory markers in experimental induced renal failure in rats by adenine. The laboratory 
investigations are kidney function tests, C-reactive protein (CRP), Interleukin 6, Lactate dehydrogenase $(\mathrm{LDH})$ and the role of $\mathrm{N}$ acetylcysteine on chronic renal failure.

\section{MATERIALS AND METHODS}

\subsection{Rats:}

Forty white male albino rats of 50-60 days old and weight 180-200 gm were used in the experimental investigation of this study. Animals were obtained from laboratory animal research center, faculty of veterinary medicine, Benha University. Rats were housed in hygienic metal cages; clean and free drinking water was supplied libitum Rats were kept at constant environmental and nutritional conditions throughout the period of the experiment. Experimental rats were kept two weeks for acclimatization before the beginning of the experiment.

\subsection{Chemicals:}

Adenine was brought from Merck Ltd., Germany, while N-acetyl cysteine and all other reagents used were of analytical grade and was obtained commercially from Sigma Company.

\subsection{Induction of chronic renal failure:}

Chronic renal failure has been demonstrated to occur in rats by oral administration of $250 \mathrm{mg} / \mathrm{kg}$. Adenine after 2 weeks (Ying-Yong et al., 2012).

\subsection{Experimental design:}

The experimental induction of chronic renal failure in male rats, were carried out by administrated of adenine. Experimental rats were randomly assigned to four equal groups each of 10 rats, placed in individual cages as follow: Group (A): Healthy control group (non-treated rats). Group (B): Experimentally chronic renal failure (Adenine injected group): Animals were injected with adenine solution orally, once daily for 4 weeks (Ying-Yong et al., 2012). Group (C): (Adenine then $\mathrm{N}$-acetyl cysteine injected group): Animals were injected with adenine solution orally, once daily two weeks then administrated with N-acetyl cysteine for two weeks (Mehdi et al., 2009). Group (D): (N-acetyl cysteine injected group then adenine): Animals were injected with $\mathrm{N}$-acetyl cysteine solution orally, once for two weeks then were administrated with adenine for two weeks. Blood samples were collected twice, all over the experimental period after two and four weeks. To determine the biochemical alternations and inflammatory markers in experimental induced renal failure in rats by adenine. The laboratory investigations are kidney function tests, C reactive protein (CRP), Interleukin 6, Lactate dehydrogenase (LDH). And role of $\mathrm{N}$ acetylcysteine on chronic renal failure.

\subsection{Statistical analysis:}

All data were expressed as mean $\pm \mathrm{SE}$. A oneway analysis of variance (ANOVA) was employed for comparison of means of the different groups.

\section{RESULTS}

Oral administration of adenine $250 \mathrm{mg} / \mathrm{kg}$. b.w resulted in a significant increase in urea and creatinine concentrations compared to normal control group $(P<0.01)$ while, administration of $\mathrm{N}$ acetyl cysteine for two weeks after 28 days result in decrease in serum urea and creatinine concentration compared to group B (chronic renal failure group) so, $\mathrm{N}$-acetyl cysteine has a protective effect in chronic renal failure as tabulated in table (1) and table (2).

Table (3 and 4) showed that oral administration of adenine resulted in a significant increase in CRP and Interleukin 6 concentration compared to control group, while, administration of N-acetyl cysteine for two weeks after 28 days result in decrease in C-RP and IL-6. Table (5): showed that increase in LDH concentration compared to control group while, administration of $\mathrm{N}$-acetyl cysteine for two weeks after 28 days result in decreased in LDH concentration.

Table (1): Effect of chronic renal failure on Urea concentration and role of N-acetyl cysteine on it.

\begin{tabular}{lcc}
\hline \multicolumn{1}{c}{ Group } & Urea After 14 days & Urea After 28 days \\
\hline A (Healthy control group) & $36.26 \pm 0.24^{\mathrm{c}}$ & $35.56 \pm 0.40^{\mathrm{d}}$ \\
B (Adenine injected group) & $158.14 \pm 1.27^{\mathrm{a}}$ & $261.51 \pm 1.94^{\mathrm{b}}$ \\
C (Adenine then N-acetyl cysteine injected group) & $32.74 \pm 0.21^{\mathrm{c}}$ & $98.51 \pm 18.01^{\mathrm{a}}$ \\
D (N-acetyl cysteine injected group then adenine) & $91.01 \pm 1.52^{\mathrm{b}}$ & $45.28 \pm 3.73^{\mathrm{c}}$ \\
\hline
\end{tabular}


Table (2): Effect of chronic renal failure on Creatinine concentration and role of $\mathrm{N}$-acetyl cysteine on it.

\begin{tabular}{lcc}
\hline \multicolumn{1}{c}{ Group } & Creatinine After 14 days & Creatinine After 28 days \\
\hline A (Healthy control group) & $1.1 \pm 2.90^{\mathrm{c}}$ & $1.04 \pm 4.35^{\mathrm{c}}$ \\
B (Adenine injected group) & $2.54 \pm 6.83^{\mathrm{a}}$ & $4.64 \pm 0.17^{\mathrm{a}}$ \\
C (Adenine then N-acetyl cysteine injected group) & $1.03 \pm 0.14^{\mathrm{c}}$ & $2.4 \pm 0.20^{\mathrm{b}}$ \\
D (N-acetyl cysteine injected group then adenine) & $2.1 \pm 0.26^{\mathrm{b}}$ & $0.49 \pm 2.80^{\mathrm{d}}$ \\
\hline
\end{tabular}

Table (3): Effect of chronic renal failure on $\mathrm{C}$ - reactive protein (CRP) concentration and role of $\mathrm{N}$-acetyl cysteine on it.

\begin{tabular}{lcc}
\hline \multicolumn{1}{c}{ Group } & CRP After 14 days & CRP After 28 days \\
\hline A (Healthy control group) & $6.9 \pm 0.40^{\mathrm{c}}$ & $6.7 \pm 0.46^{\mathrm{d}}$ \\
B (Adenine injected group) & $32.31 \pm 1.68^{\mathrm{b}}$ & $48.95 \pm 1.41^{\mathrm{a}}$ \\
C (Adenine then N-acetyl cysteine injected group) & $7.7 \pm 0.46^{\mathrm{c}}$ & $32.83 \pm 1.67^{\mathrm{b}}$ \\
D (N-acetyl cysteine injected group then adenine) & $43.94 \pm 0.83^{\mathrm{a}}$ & $11.91 \pm 0.52^{\mathrm{c}}$ \\
\hline
\end{tabular}

Table (4): Effect of chronic renal failure on Interleukin 6 (IL-6) concentration and role of N-acetyl cysteine on it.

\begin{tabular}{lcc}
\hline \multicolumn{1}{c}{ Group } & IL-6After 14 days & IL-6After 28 days \\
\hline A (Healthy control group) & $27.04 \pm 2.31^{\mathrm{C}}$ & $26.51 \pm 2.44^{\mathrm{d}}$ \\
B (Adenine injected group) & $65.5 \pm 2.00^{\mathrm{a}}$ & $83.86 \pm 2.44^{\mathrm{d}}$ \\
C (Adenine then N-acetyl cysteine injected group) & $28.41 \pm 2.29^{\mathrm{c}}$ & $65.98 \pm 2.04^{\mathrm{b}}$ \\
D (N-acetyl cysteine injected group then adenine) & $56.95 \pm 1.82^{\mathrm{b}}$ & $49.86 \pm 0.98^{\mathrm{c}}$ \\
& & \\
\hline
\end{tabular}

Table (5): Effect of chronic renal failure on Lactate Dehydrogenase (LDH) concentration and role of N-acetyl cysteine on it.

\begin{tabular}{lcc}
\hline \multicolumn{1}{c}{ Group } & LDH After 14 days & LDH After 28 days \\
\hline A (Healthy control group) & $255.86 \pm 9.50^{\mathrm{C}}$ & $257.7 \pm 9.80^{\mathrm{C}}$ \\
B (Adenine injected group) & $471.7 \pm 4.40^{\mathrm{b}}$ & $367.95 \pm 19.48^{\mathrm{b}}$ \\
C (Adenine then N-acetyl cysteine injected group) & $60.71 \pm 3.95^{\mathrm{d}}$ & $250.21 \pm 24.88^{\mathrm{c}}$ \\
D (N-acetyl cysteine injected group then adenine) & $889.04 \pm 11.75^{\mathrm{a}}$ & $924.87 \pm 34.11^{\mathrm{a}}$ \\
\hline
\end{tabular}

\section{DISSCUSION}

The present study showed that increased in urea concentration that, was in agreement with the result of Dimkovic et al. (2002) who found that, the mean level of BUN was significantly higher in patients with severe uremic when simply compared with those of other groups and the multiple logistic regression analysis indicated that a high level of BUN was a significant risk factor for severe uremic pruritus. In other study, Narita et al. (2006) found that high BUN levels were a significant risk factor for severe uremic pruritus.

Also, there is increased in creatinine concentration, this result is agree to that reported by Nariman et al. (2012) who noted that, the assessment of the kidney function tests revealed that serum creatinine level reached the peak of elevation in the HD group followed by CKD patients $(P<0.01)$ compared to control group. At the same time, serum urea levels showed a highly 
significant increase $(P<0.01)$ in HD followed by CKD compared to control group.

Moreover, the results revealed that, elevated CRP levels have been described in a significant proportion of end-stage-renal disease patients on hemodialysis or peritoneal dialysis (Arici and Walls, 2006). About one-third of patients with chronic renal failure have serum CRP concentration $>10 \mathrm{mg} / \mathrm{l}$ (Owen and Lowrie, 2008). These results came in agreement with Arici and Walls (2006); Ikizler et al. (2009); Noh et al. (2008); Owen and Lowrie (2008) who found that; the relation between elevated level of CRP and uremic patients. Furthermore, IL-6 increased significantly in hemodialysis patients in compared to control group. Similar findings were reported by Kimmel et al. (2006) who elaborated that HD patients with pruritus exhibit a significantly higher portion of Th1 cells, higher serum C-reactive protein (CRP) and interleukin (IL-6) levels, providing support for the role of micro-inflammation in the pathogenesis of uremic pruritus. In addition, serum levels of inflammatory biomarkers, such as C-reactive protein and IL-6 are increased in patients with UP, which confirms the inflammatory nature of the disease.

Also, Vink et al. (2004) recorded an increase in serum level of IL-6 in patients with chronic renal failure. In addition, Memoli et al. (2007) revealed an increased spontaneous release of IL-6 and TNF$\alpha$ by peripheral blood leukocytes in HD patients and the increased release of IL- 6 in the course of HD session. Engelberts and Leunissen (2004) reported an increased IL-6 serum levels in HD patients at each of the studied time points during hemodialysis session. This supports the findings of this study; the concentration of IL-6 in peripheral blood was increased in HD patients compared with non-renal failure patients or healthy individuals.

\section{CONCLUSION}

In conclusion, traditional measures of renal damage, creatinine and elevated BUN, usually occur after significant kidney damage has occurred. The results of this investigation are in general agreement with the majority of the published work in the literature and added a new knowledge to importance of understanding the biochemical profiles in chronic renal failure and importance of using N-Acetyl cysteine in renal failure patients to improve kidney function test for example decrease level of urea, creatinine, CRP, IL6 and LDH.

\section{REFERENCES}

Andereoli, S.P., 1999. Management of ARF In Pediatric Nephrology by Barratt TM, Arner ED, and Harmon WL, 4th ed. Lippincott, Pensylvenia.

Arici, M., Walls, J., 2006. End-stage renal disease, atherosclerosis and cardiovascular mortality: is $\mathrm{C}$-reactive protein the missing link? . Kidney Int 59, 407- 414.

De Caro, L., Ghizzi, A., Costa, R., 2006. Pharmacokinetics and bioavailability of oral acetylcysteine in healthy volunteers Arzneim Forsch 39, 382- 385.

De Vries, N., De Flora, S., 2003. N-Acetyl-1Cysteine. J Cell Biochemistry 17F S270S277.

Dimkovic, N., Djukanovic, L., Radmilovic, A., 2002. Uremic pruritus and skin mast cells Nephron 61, 5-9.

Engelberts, F., Leunissen , K.M., 2004. Effect of hemodialysis on peripheral blood monocyte tumor necrosis factor $\alpha$, Interleukin 6 and interleukin 8 , secretion in vivo. Nephron 396-403.

Gunsch, 2012. Renal failure is the partial or complete failure of the kidneys to function Journal of the American Chemistry Society 134, 11358-11361.

Ikizler, T.A., Wingard, R.L., Harvell, J., Shyr, Y., Hakim, R.M., 2009. Association of morbidity with markers of nutrition and inflammation in chronic hemodialysis patients: a prospective study Kidney Int 55 .

Issels, R.D., Nagele, A., Eckert, K.G., Wilmanns, W., 2008. Promotion of cystinn uptake and its utilization for glutathione biosynthesis induced by cysteamine and $\mathrm{N}$-acetylcysteine Biochem Pharmacol 37, 881-888.

Kimmel, M., Alscher, D.M., Dunst, R., Braun, N., Machleidt, C., Kiefer, 2006. The role of micro-inflammation in the pathogenesis of uraeic pruritus in haemodialysis patients Nephrol dial transplant 21, 749-755.

Mehdi, K., Majid, S., Kiyanush, F., 2009. Islamic Azad University Pharmaceutical Branch, Tehran, Iran.Research Center of Chemical Injuries, Baqiyatallah University of Medical Sciences, Tehran, Iran Department of Nephrology, Shahid Beheshti University of Medical Sciences, Tehran, Iran. 
Memoli, B., Libetta, C., Rampino, T., 2007. Interleukin 6 production of uremic hemodialysis patients, effects of different membranes Nephrol Dial transplant 96-98.

Nariman, Z., Iman, W., Azza, S., Manal, Z., 2012. Granulocyte macrophage colony stimulating factor mediated modulation of polymorphonuclear leukocyte dysfunction in chronic kidney disease and hemodialysis patients Jouranl of American science 8, 731773.

Narita, I., Alchi, B., Omori, K., Sato, F., Ajiro, J., Saga, K., Skatsume, D., 2006. Etiology and prognostic significance of severe uremic pruritus in chronic hemodialysis patients Kidney int 69, 1626.

Naughton, C.A., 2008. Drug-induced nephrotoxicity. Am Fam Physician 78, 743 750 .

Noh, H., Lee, S.W., Kang, S.W., Shin, S.K., Choi, K.H., Lee, H.Y., Hans, D.S., 2008. Serum Creactive protein: a predictor of mortality in continuous ambulatory peritoneal dialysis patients Perit Dial Int 18, 387-394.

Owen, W.F., Lowrie, E.G., 2008. C-reactive protein as an outcome predictor for maintenance hemodialysis patients Kidney Int 54, 627-636.

Van holder, R., Griet, L., Glorieux, 2003. An overview of uremic toxicity hemodial Int. 7 , 156-161.

Vink, A., Uyettenhove, P., Waunders, P., Van, S., 2004. Accassory fain murine $\mathrm{T}$ cell activation.Distinct roles of interleukin 6 , interleukin 1 and tumor necrosis factor. Eur J Immunol 20, 1-6.

Ying-Yong, Z., Xian-Long, C., Ji-Hong, C., XingRong, Y., Feng, W., Xu, B., Rui-Chao, L., 2012. A Key Laboratory of Resource Biology and Biotechnology in Western China, Ministry of Education, the College of Life Sciences, Northwest University, No.229 Taibai North Road, Xi'an, Shaanxi 710069, China .B , 2 Tiantan Xili, Beijing, 100050, China .C Waters Technologies (Shanghai) Ltd. . National Institutes for Food and Drug Control, State Food and Drug Administration, Shanghai, China.

Ziment, I., 2007. Acetylcysteine: a drug that is much more than a muco-kinetic Biomed Pharmaco ther 42, 513-520. 